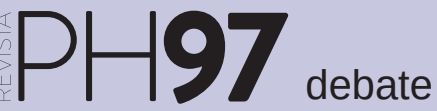

a debate El papel del patrimonio en las nuevas políticas para la cultura, la ciudad y el territorio:

las agendas urbanas como marco de oportunidad

| coordinan Blanca del Espino Hidalgo, Rafael Merinero Rodríguez

\title{
El "amable" urbanismo de mercado. Patrimonio e identidad como elementos competitivos fundamentales
}

\author{
Daniel Martínez Castizo | historiador y antropólogo \\ URL de la contribución <http://www.iaph.es/revistaph/index.php/revistaph/article/view/4397>
}

El pretendido esfuerzo de las instituciones europeas, así como el de sus Estados miembros, por garantizar la cohesión económica, social y territorial, se encuentra, desde hace décadas, en una perpetua contradicción de la que no quiere salir. La misma parte del hecho de haber asociado dichos objetivos al término "desarrollo sostenible" y éste, a su vez, a un modelo socioeconómico que, siguiendo con las doctrinas de la economía de mercado y los intereses del establishment, propone una realidad que, pese a encontrarse en un irremediable estado de progresiva degradación, apunta a ser mejorable a través de un modelo de bienestar en perpetua reinvención.

Aparentemente siempre hay nuevas recetas con las que superar esta problemática realidad estructural (a la que nos aboca el capitalismo europeo), sobe todo a través de proyectos paliativos que las instituciones crean para contener las posibles fisuras sociales que pongan en riesgo el sistema. En esa línea es en la que debemos ubicar y entender la última gran Cumbre de Desarrollo Sostenible (septiembre de 2015), que dio lugar a la Agenda 2030 basada en 17 objetivos, entre los que se encuentra el 11 dedicado a "Ciudades y Comunidades Sostenibles" con el objetivo principal de "lograr que las ciudades y los asentamientos humanos sean inclusivos, seguros, resilientes y sostenibles"-; y que a la postre vino a dar el impulso definitivo al proyecto de la Agenda Urbana.

Este proyecto urbano, a escala europea, podría compararse con el iniciado hace décadas en el mundo rural y que terminó por denominarse Nueva Ruralidad. Empero, las políticas y programas vinculados a recuperar el mundo rural no partieron de la base de poner fin a los problemas que provocaron su depauperación socioeconómica -convirtiéndolo en un espacio de acopio de recursos naturales y mano de obra-, sino que, más bien, apostaron por "integrar" a éste en el mercado mediante el aprovechamiento del patrimonio cultural y natural. De esta forma, hicieron un producto amable, rentable y atractivo para un mundo urbano monótono, homogéneo y excluyente.

Pues bien, ahora se trata de convertir en "inclusivos, seguros, resilientes y sostenibles" a todas aquellas ciudades modernas diseñadas funcional e ideológicamente para ser productivas. Pero, al igual que pasó con el mundo rural, la "mejora" de lo urbano no va a partir de las premisas de cambiar el modelo productivo sino que, manteniendo la función financiera, industrial y de servicios actual, la ciudad debe también servir de referente para llevar una vida plácida, confortable y socialmente justa explotando nuevos nichos de empleo más respetuosos con el medio.

Por ello, y al igual que ocurrió con lo rural, todo va a partir de la explotación planificada del patrimonio cultural y la identidad de las ciudades. Se trata de dar forma a un "amable" urbanismo de mercado en el que la principal ventaja comparativa de las ciudades no será el haber superado las barreras que supone gestionar una ciudad desde una óptica patriarcal y capitalista (como pasa con la turistificación y gentrificación que despersonaliza las ciudades), sino que, más bien, potenciará ciertos elementos del patrimonio e identidad que aporta ventaja comparativa frente al resto y, convertirla así, en un polo atrayente de servicios y divisas.

Por tanto, si bien parece que las agendas urbanas pueden convertirse en una herramienta más (al margen de la legislación existente: Ley 14/2007, de 26 de noviembre, del Patrimonio Histórico de Andalucía o Ley 16/1985, de 25 de junio, del Patrimonio Histórico Español), para sal- 
_a debate El papel del patrimonio en las nuevas políticas para la cultura, la ciudad y el territorio: las agendas urbanas como marco de oportunidad | coordinan Blanca del Espino Hidalgo, Rafael Merinero Rodríguez

var del olvido, la degradación, destrucción y desaparición del patrimonio cultural presente en las ciudades, no podemos hacer de tripas corazón y olvidar que la filosofía que está detrás de dicha acción es puramente crematística.

Entonces, correremos el riesgo de apoyar proyectos de revalorización donde no habrá más que cálculos de rentabilidad económica que, de no cumplirse, olvidará la función social del bien y hará que todos los esfuerzos aplicados por parte de la comunidad se pierdan sin más (como otras tantas veces ya ha pasado). Quedando, irremediablemente, expuesto al olvido, la degradación, su destrucción y posterior desaparición.

La Agenda Urbana no supone un cambio de paradigma en la participación y gestión del patrimonio y la identidad de las ciudades. Es un punto y seguido, una remasterización del modelo aplicado hasta la actualidad que encontrará, a lo largo de su puesta en marcha, los mismos problemas, las mismas soluciones y, por ende, los mismos fracasos: convertir el patrimonio y la identidad en elementos competitivos de usar y tirar. 